\title{
TURNOVER DAN STRATEGI ORGANISASI UNTUK MENGATASINYA MELALUI PEMBERDAYAAN KARYAWAN
}

\author{
Dewi H. Harahap \\ Tri Welas Asih \\ Arundati Shinta \\ Universitas Proklamasi 45 Yogyakarta \\ arundatishinta@yahoo.com \\ Siti Mahmudah \\ Universitas Islam Negeri Maulana Malik Ibrahim Malang
}

\begin{abstract}
Abstrak
Turnover merupakan strategi yang sering dilakukan oleh karyawan yang belum berpengalaman kerja. Mereka lebih cepat merasa tidak puas bila menghadapi situasi yang tidak menyenangkan dalam organisasi. Reaksi spontan yang pertama kali ditampakkan adalah langsung keluar dari organisasi. Turnover pada karyawan ini sangat merugikan organisasi, karena karyawan adalah aset dari organisasi. Kerugian organisasi semakin parah ketika pelaku turnover itu tidak hanya karyawan baru tetapi karyawan yang sudah berpengalaman tinggi serta sudah sering mengikuti pelatihan. Organisasi harus berbenah menghadapi permasalahan ini. Strategi yang dilakukan untuk mengatasi permasalahan turnover ini ialah melakukan kesepakatan kerja dengan karyawan baru. Kesepakatan kerja tersebut berisi beberapa hal yaitu: 1). Jangka waktu yang diijinkan bagi karyawan baru yang diterima untuk mengundurkan diri. 2). Karyawan yang sudah diterima namun belum habis masa kontraknya dan ingin mengundurkan diri, maka ia diharuskan mengganti biaya pelatihan. Strategi selanjutnya untuk memunculkan dorongan berprestasi dan motivasi internal adalah memberi penekanan bahwa kepemimpinan tidak hanya berada pada pengelola manajemen saja, tetapi juga berada dalam setiap diri karyawan. Pemberdayaan ini akan membuat karyawan jeli pada segala sesuatu yang ada dalam organisasi. Kejelian itu akan membuat potensi karyawan tergali dengan optimal, sehingga kepuasan kerjanya tinggi, dan intensitas turnout menjadi rendah. Pemberdayaan diri itu bisa melalui kegiatan studi lanjut, memberikan tantangan kerja, memberi kebebasan untuk berinovasi dalam menyelesaikan tugasnya, dan menjamin adanya keamanan kerja. Selanjutnya organisasi juga dapat menawarkan promosi jabatan berdasarkan prestasi kerja, buka senioritas. Situasi kondusif seeperti ini akan mengurangi intensi untuk turnout.
\end{abstract}

Kata kunci: turnover, kinerja karyawan, motivasi kerja.

Turnover adalah keluarnya karyawan dari suatu organisasi tempatnya bekerja. Turnover memang merugikan organisasi, meskipun ada juga turnover yang justru menguntungkan organisasi (Robbins, 1998). Organisasi akan menderita 
kerugikan bila karyawan yang keluar adalah karyawan yang sudah berpengalaman tinggi, mempunyai kemampuan tinggi dan mempunyai posisi penting. Sebaliknya, organisasi justru akan beruntung, bila karyawan yang keluar tersebut mempunyai posisi tidak penting (marginal). Posisi yang ditinggalkannya akan diisi oleh karyawan lainnya yang sudah menunggu promosi. Pada umumnya, tunover pada organisasi berdampak negatif.

Demikian pentingnya isu turnover ini, sehingga isu tersebut telah menjadi salah satu variabel tergantung pada banyak penelitian (Robbins, 1998). Turnover ini berkaitan dengan kepuasan kerja (Medina, 2012). Oleh karena itu organisasi berusaha keras agar para karyawannya mempunyai kepuasan kerja tinggi, sehingga mengurungkan niatnya untuk turnover. Usaha-usaha organisasi tersebut berkaitan dengan tingkat kepedulian pemimpin pada karyawannya. Semakin ia peduli maka semakin rendah kecenderungan karyawan untuk turnover. Kepedulian pemimpin itu biasanya berbentuk program-program pemberdayaan karyawan. Contoh program adalah kesempatan untuk menimba ilmu lanjutan. Persoalannya adalah tidak semua karyawan jeli dengan program-program tersebut. Mungkin saja karyawan justru merasa terbebani oleh program-program tersebut.

Jadi permasalahan dalam tulisan ini adalah karyawan kurang jeli melihat peluang-peluang yang ditawarkan pimpinan organisasi untuk memberdayakan dirinya. Karyawan kurang mempunyai dorongan berprestasi (nAch, need for achievement) yang tinggi. Dampaknya, bila karyawan sedikit saja merasa tidak puas dengan pekerjaannya maka kecenderungannya adalah turnover. Kalau pun tetap setia pada organisasi, maka kesehatan mentalnya mungkin terganggu. la merasa terpenjara oleh pekerjaan dan organisasinya (Huysse-Gaytandjieva, Groot, \& Pavleva, 2013).

Tujuan tulisan ini adalah untuk menjelaskan tentang strategi organisasi untuk pemberdayaan karyawan sehingga kecenderungannya untuk turnover menjadi berkurang. Tulisan ini lebih berpihak kepada karyawan, karena di depan organisasi / pimpinan, karyawan sering merasa subordinat. Manfaat tulisan adalah untuk memberi pencerahan pada karyawan bahwa apa pun kondisi organisasi, ternyata ada sisi-sisi positif yang bisa digali. Proses penggalian sisi positif itu sebenarnya adalah proses pemberdayaan karyawan. Karyawan yang merasa tidak puas dengan pekerjaannya tidak perlu turnover atau terganggu kesehatan mentalnya.

Tulisan ini penting karena dua alasan. Pertama, angka pengangguran tinggi sehingga alternatif pekerjaan di luar organisasi sangat sedikit. Oleh karena itu bila keputusan karyawan untuk segera turnover ketika ia merasa tidak puas dengan pekerjaannya, maka hal itu kurang bijaksana. Kedua, semakin sering karyawan 
turnover maka semakin sedikit peluangnya untuk mengembangkan karir. la kehabisan waktu, karena selalu meniti karir dari bawah dan tidak pernah berada di puncak. Sebenarnya karir justru bisa berkembang dengan baik ketika karyawan berani menghadapi tantangan atau tetap berada dalam organisasi sambil mengembangkan diri. Tetap berada dalam organisasi sambil mengembangkan diri berarti ia jeli melihat berbagai peluang yang ditawarkan organisasi.

\section{Turnover Dalam Organisasi}

Turnover secara ringkas berarti karyawan keluar dari organisasi (Evendi \& Dwiyanti, 2013; Moorhead \& Griffin, 1995). Turnover itu bisa dilakukan secara suka rela maupun terpaksa (Robbins, 1998). Turnover yang dilakukan karena terpaksa, biasanya hal itu terjadi karena organisasi mengalami kebangkrutan, sehingga organisasi harus memberhentikan karyawannya. Turnover seperti ini adalah keputusan pimpinan, bukan keputusan karyawan. Karyawan juga terpaksa melakukan turnover ketika ia mencapai usia pensiun, mengalami penyakit atau cacat tubuh (Shaw, Delery, Jenkins Jr., \& Gupta, 1998). Turnover yang sifatnya suka rela biasanya terjadi pada karyawan yang merasa tidak puas dengan keadaan organisasinya tempat bekerja. Jadi hubungan antara turnover dan kepuasan kerja adala korelasi negatif (Medina, 2012). Turnover suka rela juga bisa terjadi ketika organisasi menawarkan program pensiun dini, untuk mempertahankan usia organisasi (Shaw, Delery, Jenkins Jr., \& Gupta, 1998).

Apakah turnover itu merugikan organisasi? Turnover akan merugikan atau menguntungkan organisasi berdasarkan faktor kualitas karyawan. Bila karyawan yang keluar adalah karyawan yang pengalaman kerjanya tinggi, kualitas kerjanya bagus karena sudah mendapatkan berbagai pelatihan dari organisasi dan memegang posisi penting, maka organisasi akan mengalami kerugian besar. Kerugian terjadi karena organisasi sudah mengeluarkan banyak dana untuk mengembangkan karyawan, namun karyawan segera keluar setelah mendapatkan manfaat. Selain itu, kualitas yang bagus dari karyawan telah menyebabkan organisasi tergantung nasibnya pada karyawan tersebut. Apalagi bila karyawan yang berkualitas bagus itu belum sempat / enggan menularkan kemampuannya pada karyawan lain.

Dampak buruk turnover selanjutnya pada organisasi adalah turnover menular pada karyawan lainnya (Nasution, 2009). Organisasi-organisasi yang mempunyai sejarah angka turnover yang tinggi berdasarkan berbagai alasan, cenderung membuat karyawan lama untuk juga keluar (Shaw et al., 1998). Terus berada dalam organisasi dengan sejarah turnover tinggi mungkin akan membuat karyawan lama 
semakin tidak percaya pada organisasi. Apalagi bila mantan karyawan itu ternyata menjadi lebih sukses setelah bekerja pada organisasi lain. Dampak buruk selanjutnya adalah karyawan berkualitas tinggi yang turnover itu ternyata menyebabkan pelanggan juga menghilang. Karyawan berkualitas tinggi berarti ia sudah menghayati rahasia organisasi dalam menarik pelanggan. Bila ia keluar dari organisasi, berarti hilang pula penggannya (Chen, Wang, Chu, 2010).

Turnover juga bisa berdampak positif pada organisasi. Bila karyawan yang keluar adalah karyawan yang belum berpengalaman, organisasi belum mengeluarkan dana untuk pengembangan karyawan, ia menduduki posisi yang tidak penting (marginal) dan ia sering merasa tidak puas dengan pekerjaannya, maka organisasi justru akan beruntung (Robbins, 1998). Keluarnya karyawan yang berkualitas rendah tersebut justru membuka peluang bagi organisasi untuk mencari karyawan baru yang kualitasnya lebih baik. Selain itu, posisi yang kosong itu merupakan peluang promosi bagi karyawan lainnya.

Mengapa terjadi turnover? Turnover terjadi karena karyawan merasa tidak puas dengan organisasi tempatnya bekerja. Tidak semua karyawan yang merasa tidak puas akan keluar dari organisasi. Selain keluar dari organisasi (exit), karyawan yang tidak puas terhadap organisasi akan melakukan tindakan lainnya yaitu berdiskusi dengan manajemen agar terjadi perubahan (voice), berdoa sambil berharap terjadi perbaikan dalam organisasi, atau berperilaku tidak peduli (neglect) (Matland, 1995; Rusbult, Farrell, Rogers, \& Mainous III, 1988; Rusbult, Zembrodt, \& Gunn, 1982).

Alternatif mana saja yang akan dipilih individu dari empat alternatif di atas, bergantung pada tiga hal. Tiga penentu keputusan individu tersebut ialah ketersediaan alternatif di luar organisasi, kemungkinan pengorbanan yang harus ditanggung bila memutuskan hubungan, dan tingkat pengalaman menyenangkan yang telah diperolehnya dengan organisasi tersebut (Michener \& DeLamater, 1999). Semakin rendah angka pengangguran, semakin sedikit pengorbanan individu kepada oranisasi dan semakin buruk pengalaman individu pada organisasi, maka semakin individu memutuskan untuk keluar dari organisasi.

Selanjutnya juga disebutkan bahwa penyebab turnover adalah banyak faktor. Faktor-faktor tersebut adalah kemenarikan pekerjaan, kemenarikan organisasi, karakter karyawan, kesesuaian antara kualitas karyawan dengan pekerjaan, angka pengangguran dan pengaruh dari keluarga (Moorhead \& Griffin, 1995). Semakin pekerjaan dipersepsikan tidak menarik dan semakin banyak alternatif pekerjaan di luar (angka pengangguran rendah), maka karyawan semakin terdorong untuk turnover (Shaw et al., 1998). Keberadaan karyawan dalam suatu organisasi adalah 
bukan kebetulan. Karyawan memilih organisasi yang disukainya. Karyawan yang rasa percaya dirinya rendah, cenderung senang dengan organisasi besar. Hal ini karena ia tidak perlu memperlihatkan tanggung jawab yang besar. Bila ia berada pada organisasi kecil, maka mungkin ia akan turnover (Turban \& Keon, 1993).

\section{Strategi Organisasi Untuk Menekan Turnover.}

Melihat begitu berartinya karyawan bagi keberlangsungan organisasi (Luthans, 1995), maka organisasi tentu saja akan mempertahankan karyawan dengan berbagai strategi. Strategi investasi langsung yang dilakukan oleh bagian personalia adalah memastikan bahwa gaji, honor, dan berbagai imbalan lainnya harus berjalan dengan lancar, baik jumlah dan waktu pembagiannya (Shaw et al., 1998). Apabila gaji tidak diterimakan secara rutin, maka karyawan akan bertanyatanya tentang kepastian usia organisasi. Salah satu tanda organisasi akan tutup adalah gaji karyawan sering tersendat.

Untuk mencegah turnover, bagian personalia juga harus melaksanakan strategi investasi yang sifatnya tidak langsung. Strategi itu meliputi stabilitas pekerjaan (ia tidak akan dipecat), pelatihan, dan keadilan prosedural. Selanjutnya strategi itu juga memastikan adanya kesempatan untuk promosi jabatan, adanya program mentoring dari karyawan senior pada karyawan junior, serta adanya saluran komunikasi yang lancar. Keberadaan strategi ini akan berkorelasi negatif dengan turnover suka rela (Chen et al., 2010; Shaw et al., 1998).

Selanjutnya, untuk meminimalkan potensi kerugian maka organisasi juga dapat menerapkan dua kebijakan yaitu:

1. Jangka waktu yang diijinkan bagi karyawan baru yang diterima untuk mengundurkan diri. Hal ini untuk menghindarkan kasus karyawan yang baru masuk beberapa hari namun kemudian ia melakukan turnover. Strategi ini untuk menjaga citra organisasi.

2. Karyawan yang sudah diterima namun belum habis masa kontraknya dan ingin mengundurkan diri, maka ia diharuskan mengganti biaya-biaya pelatihan yang telah diterimanya. Biaya pelatihan tersebut sangat mahal, sehingga karyawan harus berpikir lagi bila akan keluar dari organisasi. Berdasarkan Undang-Undang No. 13 tahun 2003 tentang Ketenagakerjaan, besarnya biaya pelatihan yang harus dikembalikan adalah sebesar upah karyawan sampai batas waktu berakhirnya jangka waktu perjanjian kerja.

Strategi-strategi tersebut di atas sebenarnya adalah indikator bahwa organisasi peka terhadap letupan-letupan rasa tidak puas karyawan. Organisasi harus segera bertindak melakukan pembenahan dan penataan kembali semua 
perangkat organisasi untuk meredam keresahan karyawan. Pembenahan itu juga harus memperhatikan suara-suara karyawan. Pembenahan organisasi yang hanya berdasarkan opini pimpinan saja (misalnya monitoring semua perilaku karyawan secara elektrik), maka hasilnya adalah karyawan justru terdorong untuk turnover secara suka rela (Chen et al., 2010; Shaw et al., 1998).

\section{Motivasi Internal dan Intensi untuk Turnout}

Adanya ungkapan-ungkapan rasa tidak puas karyawan yang kemudian diikuti dengan gelombang turnover, menunjukkan bahwa organisasi sedang tidak sehat. Untuk mencegah turnover, memang sudah seharusnya organisasi mendisain program-program kreatif. Program-program kreatif itu gunanya untuk memberdayakan karyawan. Pemberdayaan berarti karyawan ikut terlibat dalam proses pengambailan keputusan tentang jalannya organisasi. Persoalannya adalah tidak banyak karyawan yang bersedia mengikuti program-program itu. Hal ini mungkin para karyawan itu berada pada posisi penting. Mereka berada pada zona nyaman.

Untuk menggugah motivasi internal karyawan, maka organisasi dapat menekankan bahwa kepemimpinan tidak hanya berada pada pengelola manajemen saja, tetapi juga berada dalam setiap diri karyawan. Hal ini karena kepemimpinan pada hakekatnya adalah ilusi belaka. Penciptaan ilusi itu untuk memuaskan kebutuhan kita untuk bergantung pada orang lain (Allio, 2013; Shinta, Yudhawati \& Purwaningsih, 2013). Oleh karena karyawan adalah juga sebagai pemimpin, maka karyawan didorong untuk memunculkan potensinya, sehingga motivasi kerjanya lebih didominasi oleh motivasi internal. Untuk memunculkan motivasi internal karyawan sehingga karyawan jeli pada peluang-peluang yang ada pada organisasi, maka organisasi dapat menawarkan pelatihan untuk memunculkan dorongan berprestasi (nAch), memberikan tantangan dalam pekerjaan, memberikan kebebasan untuk berinovasi dalam menyelesaikan tugas, namun keamanan kerja tetap terjamin (Samuel \& Chipunza, 2009).

Selanjutnya organisasi juga dapat menawarkan promosi jabatan berdasarkan prestasi kinerja, bukan senioritas. Hal ini karena karyawan yang mempunyai dorongan berprestasi tinggi ( $\mathrm{nAch}$ ) cenderung lebih tertarik bekerja pada organisasi yang menawarkan promosi berdasarkan prestasi kerja, bukan senioritas (Turban \& Keon, 1993).

Untuk mencegah karyawan lama yang berprestasi tinggi melakukan turnover, maka organisasi dapat menawarkan program tugas belajar dengan beasiswa. Setelah menyelesaikan pendidikan lanjutan itu, maka karyawan harus mematuhi 
ketentuan organisasi yaitu $2 n+1$. Mereka harus tetap bekerja di organisasi minimal dua kali masa studi ditambah dengan satu tahun. Kebijakan ini berguna untuk menjadikan karyawan lama sebagai role model/ panutan bagi karyawan baru.

Sebagai catatan, rumus $2 \mathrm{n}+1$ tersebut diadopsi dari Peraturan Menteri Energi dan Sumber Daya Mineral No. 020/2007, dan ditujukan pada Pegawai Negeri Sipil di Departemen Energi dan Sumber Daya Mineral. Selain itu, yang dimaksud dengan studi lanjutan adalah tingkat S2 (master) dan S3 (doktor). Meskipun demikian, organisasi swasta pun dapat mengadopsi peraturan tersebut, sepanjang semua perangkat organisasi menyetujuinya.

Dorongan organisasi bagi karyawan untuk mendapatkan motivasi berprestasi melalui berbagai program pencegahan turnover, akan membuat karyawan semakin mengoptimalkan kinerjanya. la akan jeli terhadap peuang-peluang yang ada dalam organisasi tempatnya berkarya, untuk mengembangkan potensi dirinya. Semakin ia rajin mengambangkan dirinya, maka turnover akan semakin jauh dari ingatannya. la justru asyik membina karirnya.

\section{KESIMPULAN}

Tujuan tulisan ini adalah untuk menjelaskan tentang strategi organisasi untuk pemberdayaan karyawan sehingga kecenderungannya untuk turnover menjadi berkurang. Strategi organisasi yang bersifat investasi langsung adalah memastikan bahwa gaji, honor, dan berbagai bonus harus diberikan kepada karyawan baik dalam hal jumlah maupun waktu pemberiannya. Strategi investasi tidak langsung adalah berupa kesempatan bagi karyawan untuk mengembangkan diri. Disebut investasi tidak langsung karena dampaknya tidak langsung bagi pengembangan diri karyawan.

Karyawan yang mampu mengembangkan diri berarti ia mampu memberdayakan dirinya. la menjadi jeli pada peluang-peluang yang dosodorkan organisasi untuk menaikkan kemampuannya. Karyawan yang tergali potensinya akan tinggi juga kepuasan kerjanya, sehingga intensi turnover justru menurun. 


\section{DAFTAR PUSTAKA}

Allio, R. J. (2013). Masterclass: Leaders and leadership. Strategy and Leadership. 41(1), 4-14. Emerald Publishing Limited, DOI 10.1108/10878571311290016.

Chen, Y.C., Wang, W.C. \& Chu, Y.C. (2010) Structural investigation of the relationship between working satisfaction and employee turnover. The Journal of Human Resource and Adult Learning. 6(1), June, 41-50.

Evendi, R. \& Dwiyanti, R. (2013). Hubungan antara hardiness (kepribadian tahan banting) dengan intensi turnover pada karyawan PT Sumber Alfaria tbk di wilayah Gombong Kabupaten Kebumen. Psycho Idea. 11(2), Juli, 10-18. ISSN 1693-1076.

Huysse-Gaytandjieva, A., Groot, W. \& Pavleva, M. (2013). Why do some employees fall into and fail to exit a job-lock situation?. Journal of environemntal and $\begin{array}{lllll}\text { Public Health. } 2013 . & \text { Article ID } & \text { 839349. } & \text { 1-14. }\end{array}$ http://dx.doi.org/10.1155/2013/839349.

Luthans, F. (1995). Organizational behavior. 7th ed. New York: McGraw-Hill, Inc.

Matland, R. E. (1995). Exit, voice, loyalty, and neglect in urban school system. Social Science Quarterly 76 (3), 506-512, September.

Michener, H. A. \& DeLamater, J. D. (1999). Social psychology. $4^{\text {th }}$ Ed. Philadelphia: Harcourt Brace College Publishers.

Medina, E. (2012). Job satisfaction and employeen turnover intention: What does organizational culture have to do with it? Thesis of Masters of Arts. Fall. Columbia University.

Moorhead, G. \& Griffin, R. W. (1995). Organizational behavior. Boston: Houghton Mifflin Company.

Nasution, W.A., (2009). Pengaruh kepuasan kerja karyawan terhadap intensi turnover pada call center telkomsel di Medan. Jurnal Mandiri. 4(1), Februari, 1-57. ISSN 1907-4158.

Peraturan Menteri Energi dan Sumber Daya Mineral Nomor 020 tahun 2007, tentang pedoman pelaksanaan tugas belajar pendidikan pascasarjana program magister / master (S2) dan doktor (S3) dalam negeri dan luar negeri di lingkungan Departemen Energi dan Sumber Daya Mineral.

Robbins, S.P. (1998). Organizational behavior. $8^{\text {th }}$ Ed. International Edition. Upper Saddle River, New Jersey: Prentice-Hall International, Inc.

Rusbult, C. E., Farrell, D., Rogers, G., \& Mainous III, A. G. (1988). Impact of exchange variables on exit, voice, loyalty, and neglect: An integrative model 
of responses to declining job satisfaction. Academy of Management Journal, 31(3), 599-627.

Rusbult, C. E., Zembrodt, I. M., \& Gunn, L. K. (1982). Exit, voice, loyalty, and neglect: Responses to dissatisfaction in romantic involvements. Journal of Personality and Social Psychology., 43 (6), 1230-1242.

Samuel, M. O. \& Chipunza, C. (2009). Employee retention and turnover: Using motivational variables as a panacea. African Journal of Business Management. 3(8), September, 410-415. DOI: 10.5897/AJBM09.125.

Shaw, J. D., Delery, J. E., Jenkins Jr., G. D. \& Gupta, N. (1998). An organizationlevel analysis of voluntary and involuntary turnover. Academy Of Management Journal. 41(5), 511-525.

Shinta, A., Yudhawati, D. \& Purwaningsih, I. E. (2013). Pemimpin psikopat vs karyawan dalam organisasi yang lemah: Strategi memperkuat kesehatan mental karyawan. Prosiding Seminar Nasional. Fakultas Psikologi Universitas Sultan Agung Semarang, 12 Desember.

Turban, D.B. \& Keon, T.L. (1993). Organizational attractiveness: An interactionist perspective. Journal of Applied Psychology. 78(2), 184-193. 